\title{
Pseudo-lignin Retarded Bioconversion of Sugarcane Bagasse Holocellulose after Liquid Hot Water and Acid Pretreatments
}

\author{
Haiyan Yang, ${ }^{\text {a,b }}$ Yuanchen Zhu, ${ }^{\text {a,b }}$ Yan Jin, ${ }^{\text {a,b }}$ Fuhou Lei, ${ }^{c}$ Zhengjun Shi, ${ }^{\text {a,b }}$ and Jing Yang a,b,* \\ Pseudo-lignin derived from the condensation of carbohydrate degradation \\ products can retard the bioconversion of lignocellulose. In this work, liquid \\ hot water $\left(150\right.$ to $\left.190{ }^{\circ} \mathrm{C}\right)$ and $1 \% \mathrm{H}_{2} \mathrm{SO}_{4}$ pretreatments $\left(130\right.$ to $190^{\circ} \mathrm{C}$ ) \\ were used on sugarcane bagasse holocellulose for $3 \mathrm{~h}$ to generate \\ pseudo-lignin. The effects of pseudo-lignin generation on structural \\ characteristics and bioconversion of substrates were evaluated. The \\ results showed that the formation of pseudo-lignin increased the \\ hydrophobicity of the substrates. After LHW pretreatments and acid \\ pretreatments at low temperatures $\left(<150{ }^{\circ} \mathrm{C}\right)$, most of the xylans were \\ removed, yielding 2.1 to $5.4 \%$ pseudo-lignin. Increasing acid pretreatment \\ temperature to 170 and $190{ }^{\circ} \mathrm{C}$ yielded $34.3 \%$ and $93.6 \%$ pseudo-lignin, \\ respectively. After pretreatment, the accessibilities and bioconversions of \\ substrates were enhanced by degradation of xylans, increasing glucose \\ conversions and bioethanol productions of substrates from 53.2 to $85.3 \%$, \\ and 9.9 to $13.1 \mathrm{~g} / \mathrm{L}$, respectively. However, large amounts of pseudo-lignin \\ were generated during acid pretreatments at $170{ }^{\circ} \mathrm{C}$, reducing glucose \\ conversion and bioethanol yield to $45.6 \%$ and $6.3 \mathrm{~g} / \mathrm{L}$, respectively.
}

Keywords: Pseudo-lignin; Bioethanol; Enzymatic hydrolysis; Structural characteristics

Contact information: a: Key Laboratory of State Forestry and Grassland Administration on HighlyEfficient Utilization of Forestry Biomass Resources in Southwest China, Southwest Forestry University, Kunming 650224, China; $b$ : Key Laboratory for Forest Resources Conservation and Utilisation in the Southwest Mountains of China, Ministry of Education, Southwest Forestry University, Kunming 650224, China; c: Guangxi Key Laboratory of Chemistry and Engineering of Forest Products, Guangxi University for Nationalities, Nanning 530006, China; *Corresponding author: kmjingyang@ 163.com

\section{INTRODUCTION}

The rise of global energy consumption necessitates the development of renewable energy sources to address vital strategic, economic, and environmental issues related to the depletion of fossil fuels (Himmel et al. 2007). Lignocellulose is an abundant and renewable feedstock for the production of fuels and chemicals. Sugarcane bagasse, a lignocellulosic residue from agriculture, can be utilized to produce bioethanol.

Sugarcane bagasse contains appreciable amounts of cellulose (35 to 45\%), hemicelluloses (25 to $35 \%$ ), lignin (21 to $25 \%$ ), and minor amounts of extractives and inorganic compounds (Desouky et al. 2014). Carbohydrates in sugarcane bagasse can be depolymerized by chemical or enzymatic hydrolysis and further fermented by microorganisms to ethanol. However, the natural recalcitrance of cell walls makes polysaccharides difficult for microbes and enzymes to disintegrate. Thus, an essential pretreatment step is necessary to promote the accessibility of carbohydrates to attack by enzymes during hydrolysis. Among all the pretreatment technologies, liquid hot water (LHW), dilute acid (DA), and steam explosion (SE) pretreatments are commonly used to pretreat lignocellulose due to the effective removal of hemicelluloses and enhancement of 
cellulose enzymatic conversion. In addition, LHW pretreatment has attracted a significant amount of attention due to the low cost of energy and alleviated equipment corrosion in comparison with pretreatments using acidic catalyst. However, several studies have found that the acid insoluble lignin content of residues from these pretreatments to be higher than the starting material (Li et al. 2005; Leschinsky et al. 2009; Jung et al. 2010; Xiao et al. 2011; Yang et al. 2012). Even taking holocellulose as substrate, acid-insoluble composition of the sample also increased after acid pretreatment (Sannigrahi et al. 2011; Hu and Ragauskas 2014). These acid-insoluble components are termed as pseudo-lignin and deposit on the surface of cellulose. Degradation products from carbohydrate fractions are the source of pseudo-lignin (Sannigrahi et al. 2011; Shinde et al. 2018). The structure of pseudo-lignin has been found to be lignin-like, containing carbonyl, carboxylic, methoxyl, aromatic, and aliphatic groups (Shinde et al. 2018). During pretreatment, the formed pseudo-lignin can reduce cellulose accessibility and unproductive bind cellulase (Kumar et al. 2013). Pseudo-lignin has been reported to be more detrimental to the enzymatic hydrolysis than dilute acid pretreatment lignin (Hu et al. 2013). However, pseudo-lignin has lower negative surface charge, hydrophobic nature, Langmuir constant, and binding strength than residual lignin in bamboo after dilute acid pretreatment, representing weaker negative impact on enzymes than residual lignin (He et al. 2018). Thus, the inhibition effect of pseudo-lignin depends on its physical chemical characteristics. In addition, the composition and amount of pseudo-lignin vary significantly depending on the type of biomass and pretreatment condition.

In this study, different conditions were used to pretreat holocellulose of sugarcane bagasse to generate pseudo-lignin. The effect of generated pseudo-lignin on structural characteristics of residues was measured by chemical composition, Fourier transform infrared (FT-IR) spectrometry, X-ray photoelectron spectroscopy (XPS), and dye adsorption. The effect of pseudo-lignin on bioconversion of holocellulose after pretreatments was studied by enzymatic hydrolysis and simultaneous saccharification and fermentation.

\section{EXPERIMENTAL}

\section{Materials}

Sugarcane bagasse was kindly supplied by Yingmao Sugar Co., Ltd. (Yunnan Province, China). After washing with distilled water, the material was oven-dried at $50^{\circ} \mathrm{C}$. In order to alleviate the effect of lignin on bioconversion of materials, the dried sugarcane bagasse was delignified using sodium chlorite under acidic condition to prepare holocellulose for pretreatments (Yang et al. 2015).

\section{Liquid Hot Water (LHW) and Dilute Acid Pretreatments (DAPs)}

LHW pretreatments of holocellulose from sugarcane bagasse were performed in autoclaves at a solid to liquid ratio of 1:10. Then, the autoclaves were incubated in an oil bath at 150,170 , and $190^{\circ} \mathrm{C}$, respectively. DAPs were conducted in an autoclave at 130 , 150,170 , and $190{ }^{\circ} \mathrm{C}$ with $1 \% \mathrm{H}_{2} \mathrm{SO}_{4}$ at a solid to liquid ratio of $1: 10$, respectively. After $3 \mathrm{~h}$ incubation, the hydrolyzates were collected by filtration and submitted to degradation products analysis. The solid fractions were thoroughly washed with distilled water until the filtrates were neutralized, oven-dried at $50{ }^{\circ} \mathrm{C}$, and labeled according to pretreatment method and temperature. The solid samples were submitted to a list of characterizations and bioconversion. 


\section{Enzymatic Hydrolysis and Simultaneous Saccharification and Fermentation (SSF)}

The effect of pseudo-lignin on digestibilities of substrates obtained from pretreatments was investigated by enzymatic hydrolysis and SSF. The enzymatic hydrolysis experiments were carried out at substrate concentration of $5 \%(\mathrm{w} / \mathrm{v})$ in $10 \mathrm{~mL}$ of $50 \mathrm{mM}$ sodium acetate buffer ( $\mathrm{pH} 4.8)$ with an enzyme loading of 15 FPU cellulase per gram of dry weight of substrate using an air bath shaking incubator at $150 \mathrm{rpm}$ at $50{ }^{\circ} \mathrm{C}$ for $72 \mathrm{~h}$. The enzyme cocktail used in hydrolysis experiments contained 100 FPU cellulase, $70 \mathrm{IU} \beta$-glucosidase, and $50 \mathrm{mg}$ protein in $1 \mathrm{~mL}$ enzyme solution, which was kindly supplied by Shanghai Youtell Biochemical Co., Ltd., Shanghai, China. During enzymatic hydrolysis, $0.2 \mathrm{~mL}$ of hydrolyzates were sampled periodically and analyzed using a highperformance liquid chromatography (HPLC) system with a refractive index detector (RID) on an Aminex HPX-87 $\mathrm{H}$ column (Bio-Rad, Hercules, CA, USA) at $55^{\circ} \mathrm{C}$ with $5 \mathrm{mM}$ $\mathrm{H}_{2} \mathrm{SO}_{4}$ at a flow of $0.6 \mathrm{~mL} / \mathrm{min}$ for $55 \mathrm{~min}$. All enzymatic hydrolysis experiments were performed in duplicate, and the average values and corresponding deviations were given.

SSF experiments were performed in $50 \mathrm{~mL}$ flasks containing $0.5 \mathrm{~g}$ cellulosic sample, $10 \mathrm{~mL}$ sodium acetate buffer ( $\mathrm{pH} 4.8$ ), and $10 \mathrm{~g} / \mathrm{L}$ yeast extract. Prior to incubation, the mixture was sterilized in an autoclave at $121^{\circ} \mathrm{C}$ for $20 \mathrm{~min}$. The loading of cellulase and yeast (Angel Yeast Company Ltd., Yichang, China) in all SSF experiments were 20 FPU/g substrate and $3 \mathrm{~g} / \mathrm{L}$, respectively. After fermentation at $38^{\circ} \mathrm{C}$ for $24 \mathrm{~h}$, concentration of ethanol in broth was determined by HPLC system, as mentioned above. In addition, the number of yeast in each broth was accounted by hemocytometer. All SSF experiments were performed in duplicate, and average values and corresponding deviations were given.

\section{Analysis Procedures}

The contents of glucan, xylan, and lignin in samples were determined based on the standard National Renewable Energy Laboratory (NREL) protocol (Sluiter et al. 2012). The quantitative analysis of degradation products was performed on the HPLC system as mentioned above. XPS measurements were performed on a K-Alpha spectrometer (Thermo Fisher Scientific, Waltham, MA, USA) with monochromatic Al Ka X-ray source. High resolution spectra of carbon and oxygen were collected. The binding energy scale was calibrated by the $\mathrm{C} 1 \mathrm{~s}$ peak of $285 \mathrm{eV}$. X-ray powder diffraction patterns of the cellulosic samples were obtained using an XRD-6000 instrument (Shimadzu, Japan). The $\mathrm{X}$-ray diffractograms were recorded from $5^{\circ}$ to $35^{\circ}$ diffraction angle $2 \theta$ using the reflection method at a scanning speed of $2 \%$ min with $\mathrm{Ni}$-filtered $\mathrm{Cu} K \alpha$ radiation $(\lambda=1.54 \AA)$ at 40 $\mathrm{kV}$ and $30 \mathrm{~mA}$.

The surface accessibilities of samples were determined as the amount of adsorbed direct orange (DO, which enters large pores or adsorbs on surface of substrate) and direct blue (DB, which populates small pores of substrate). In detail, $0.1 \mathrm{~g}$ of sample and $1 \mathrm{~mL}$ of sodium phosphate-sodium chloride buffered $(\mathrm{pH} 6.0)$ were put into six $50 \mathrm{~mL}$ polypropylene centrifuge tubes. DO $(10 \mathrm{mg} / \mathrm{mL})$ solution was added in a series of increasing volumes $(0.2,0.5,0.75,1.0,1.5$, and $2.0 \mathrm{~mL})$ to the series of six tubes. $\mathrm{DB}$ solution $(10 \mathrm{mg} / \mathrm{mL})$ was added as the same volumes as that of DO into the tubes. Distilled water was added to make up the final volume in the centrifuge tubes to $10.0 \mathrm{~mL}$. Then, the tubes were incubated at the $60{ }^{\circ} \mathrm{C}$ for $24 \mathrm{~h}$ with shaking at $200 \mathrm{rpm}$. After incubation, the tubes were centrifuged at $10,000 \mathrm{rpm}$ for $5 \mathrm{~min}$, and the supernatants were determined by a UV-Vis spectrophotometer at 624 and $455 \mathrm{~nm}$. The amount of adsorbed dye was calculated as the difference between the concentration of the initial and final dye in the supernatant, as described previously (Chandra et al. 2008). 
The hydrophobicity was determined by the adsorption of Rose Bengal with modification (Gessner et al. 2000). Briefly, 0.04, 0.08, 0.12, 0.16, and $0.2 \mathrm{~g}$ samples were added into five tubes, with $10 \mathrm{~mL}$ distilled water and $3 \mathrm{~mL}$ dye solution $(40 \mathrm{mg} / \mathrm{L})$ added to each tube. After incubating the tubes at $50{ }^{\circ} \mathrm{C}$ for $2 \mathrm{~h}$ under shaking, the dye concentrations left in the suspensions were determined with a UV-Vis spectrophotometer at $543 \mathrm{~nm}$. The partitioning quotient (PQ) of each sample was calculated as the ratio of amount of Rose Bengal bound on surface to these released in dispersion medium. The PQ was plotted as a function of the total surface area resulting in straight lines.

\section{RESULTS AND DISCUSSION}

\section{Yields and Chemical Composition}

Under acidic and hydrothermal conditions, carbohydrates release monomeric sugars into the aqueous phase, and these can further degrade into furans, hydroxymethyl furfural, and acids. These compounds can be further condensed to form acid-insoluble enriched compounds termed as chars or pseudo-lignin (Kumar et al. 2013). After LHW pretreatments and DAPs, recoveries and chemical composition of residues are shown in Fig. 1. Sugarcane bagasse holocellulose contained $62.3 \%$ cellulose, $27.8 \%$ xylans, and $1.9 \%$ lignin $(0.7 \%$ acid-insoluble lignin and $1.2 \%$ acid-soluble lignin). After LHW pretreatments, solid recoveries and xylan contents were reduced from 73.2 to $61.9 \%$ and 27.7 to $9.9 \%$ as pretreatment temperature increased from $150{ }^{\circ} \mathrm{C}$ to $190{ }^{\circ} \mathrm{C}$, respectively. These results may reflect that $\mathrm{H}^{+}$released from water under hydrothermal condition catalyzed the degradation of glycosidic bonds and the linkages between acetyl substitutes and backbone of xylans. The released acetyl group formed acetic acid further degraded xylans (Maurya et al. 2015). With degradation of xylans, the relative contents of glucose increased from 62.3 to $75.5 \%$. The acid-insoluble lignin also increased from 0.7 to $2.9 \%$ with degradation of xylans. Compared with LHW pretreatments, more carbohydrates were degraded during DAPs, yielding $58.5 \%$ to $29.3 \%$ residues with minimal amount of xylans as pretreatment temperature increased from $130{ }^{\circ} \mathrm{C}$ to $170{ }^{\circ} \mathrm{C}$. The acid insoluble lignin increased to $34.4 \%$ as carbohydrates decreased in residues. However, DAP at $190{ }^{\circ} \mathrm{C}$ led to carbonization of materials, making acid-insoluble lignin as the main compound of the residue (93.6\%).

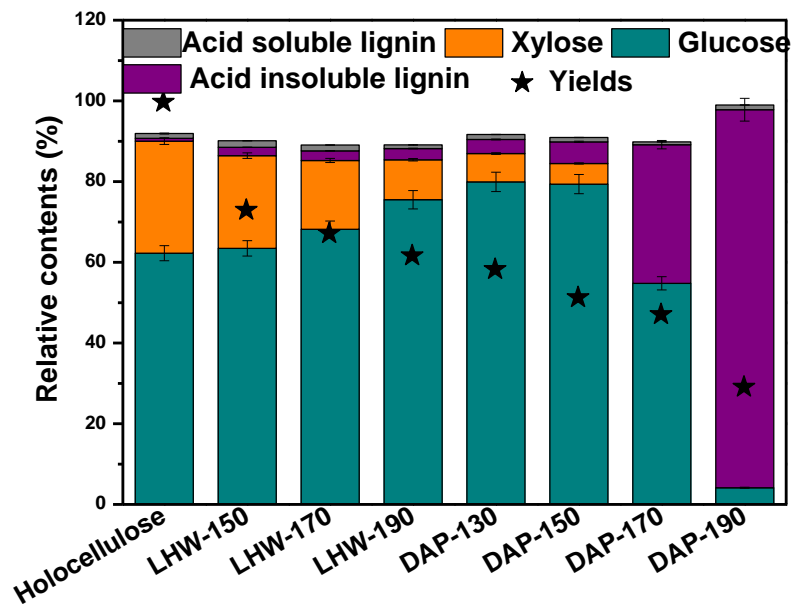

Fig. 1. Chemical composition of holocellulose and residues obtained from pretreatments 
The compounds determined in hydrolyzates were consistent with the degradation of carbohydrates. The concentrations of glucose, xylose, FF, and HMF in hydrolyzates increased with pretreatment temperature (Table 1). However, these concentrations decreased as temperature increased to 170 and $190{ }^{\circ} \mathrm{C}$ under acidic conditions. These results suggested that degradation products might participate in reactions to form pseudolignin, introducing $34.4 \%$ and $93.6 \%$ acid insoluble lignin in solids, respectively. In acidic sugar degradation pathways, furfural (FF) and 5-hydromethylfurfural (HMF) are the main dehydration products of pentoses and hexoses, respectively, and they can rearrange to yield other aromatic compounds. For instance, FF can form 3,8-dihydroxy-2-methylchromone (DMC) (Popoff and Theander 1972), while the hydrolytic ring-open reaction of HMF generates 1,2,4-benzenetriol (BTO) (Luijkx et al. 1993; Chuntanapum and Matsumura 2009). Both DMC and BTO are the key intermediates for the formation of pseudo-lignin during DAP (Hu et al. 2012). Pseudo-lignin was also observed in the holocellulose from poplar after LHW and acid pretreatments (Hu et al. 2012; Sannigrahi et al. 2011; Zhuang et al. 2017). The pronounced amount of pseudo-lignin obtained after DAPs in this study might be ascribed to the long pretreatment time and high temperature.

Table 1. Chemical Composition of Degradation Compounds in the Hydrolyzates from LHW Pretreatments and DAPs (mg/L)

\begin{tabular}{|l|c|c|c|c|c|c|c|}
\hline & Glucose & Xylose & $\begin{array}{c}\text { Formic } \\
\text { acid }\end{array}$ & $\begin{array}{c}\text { Acetic } \\
\text { acid }\end{array}$ & $\begin{array}{c}\text { Levulinic } \\
\text { acid }\end{array}$ & $\begin{array}{c}\text { Hydroxy } \\
\text { methylfur } \\
\text { fural }\end{array}$ & Furfural \\
\hline LHW-150 & 19.60 & 63.73 & 8.56 & 75.15 & ND & ND & ND \\
\hline LHW-170 & 21.37 & 69.64 & 10.64 & 71.20 & ND & ND & ND \\
\hline LHW-190 & 20.85 & 77.94 & 14.74 & 97.18 & ND & ND & ND \\
\hline DAP-130 & 53.35 & 98.65 & 115.30 & 87.07 & ND & ND & ND \\
\hline DAP-150 & 76.57 & 107.97 & 119.93 & 97.39 & 10.20 & 8.65 & 28.39 \\
\hline DAP-170 & 92.41 & 65.32 & 126.14 & 98.55 & 12.96 & 17.61 & 38.49 \\
\hline DAP-190 & 85.24 & 9.61 & 164.19 & 114.62 & 195.39 & 30.56 & 56.18 \\
\hline
\end{tabular}

Note: ND, not determined.

\section{XPS Spectra}

X-ray photoelectron spectroscopy is used to determine the elemental composition and the locations of atoms in samples (Kocaefe et al. 2013). The chemical shifts for carbon (C) and oxygen (O) in holocellulose, DAP-170, and DAP-190 are shown in Figs. 2a and b, respectively. The peaks at 285, 286, and $288 \mathrm{eV}$ correlated to $\mathrm{C}-\mathrm{C} / \mathrm{C}-\mathrm{H}, \mathrm{C}-\mathrm{O}$, and $\mathrm{C}=\mathrm{O} / \mathrm{O}-$ $\mathrm{C}-\mathrm{O}$ linkages, respectively. In holocellulose, $\mathrm{C}-\mathrm{O}$ was the predominant linkage, followed by $\mathrm{C}-\mathrm{C} / \mathrm{C}-\mathrm{H}$ and $\mathrm{C}=\mathrm{O} / \mathrm{O}-\mathrm{C}-\mathrm{O}$ linkages. After DAPs at $170{ }^{\circ} \mathrm{C}$, the amount of $\mathrm{C}-\mathrm{C} / \mathrm{C}-\mathrm{H}$ linkages increased alongside a decrease in $\mathrm{C}-\mathrm{O}$ and $\mathrm{C}=\mathrm{O} / \mathrm{O}-\mathrm{C}-\mathrm{O}$ linkages. The absence of peaks for $\mathrm{C}-\mathrm{O}$ and $\mathrm{C}=\mathrm{O} / \mathrm{O}-\mathrm{C}-\mathrm{O}$ in the spectrum of DAP 190 confirmed carbonization of holocellulose under this condition. In the spectra of oxygen, the intensity of the C-O peak also decreased after DAPs. These phenomena indicated that $\mathrm{C}-\mathrm{O}$ of holocellulose was broken under acidic condition. The drastic decrease of intensities of peaks for $\mathrm{C}-\mathrm{O}$ and $\mathrm{O}$ suggested that the oxygen-containing functional groups might participate in condensation reactions with the formation of pseudo-lignin during pretreatments (Ma et al. 2015). The 
dissociated groups participated condensation reaction to form unconjugated ketones and carbon-carbon bonds in pseudo-lignin (He et al. 2008). The increased intensity of the peak for $\mathrm{C}-\mathrm{C}$ bonds was evidence of condensation reactions. In a previous study, 1,2,4trisubstituted benzene compound was isolated from acid pretreated hybrid poplar holocellulose (Hu et al. 2012).
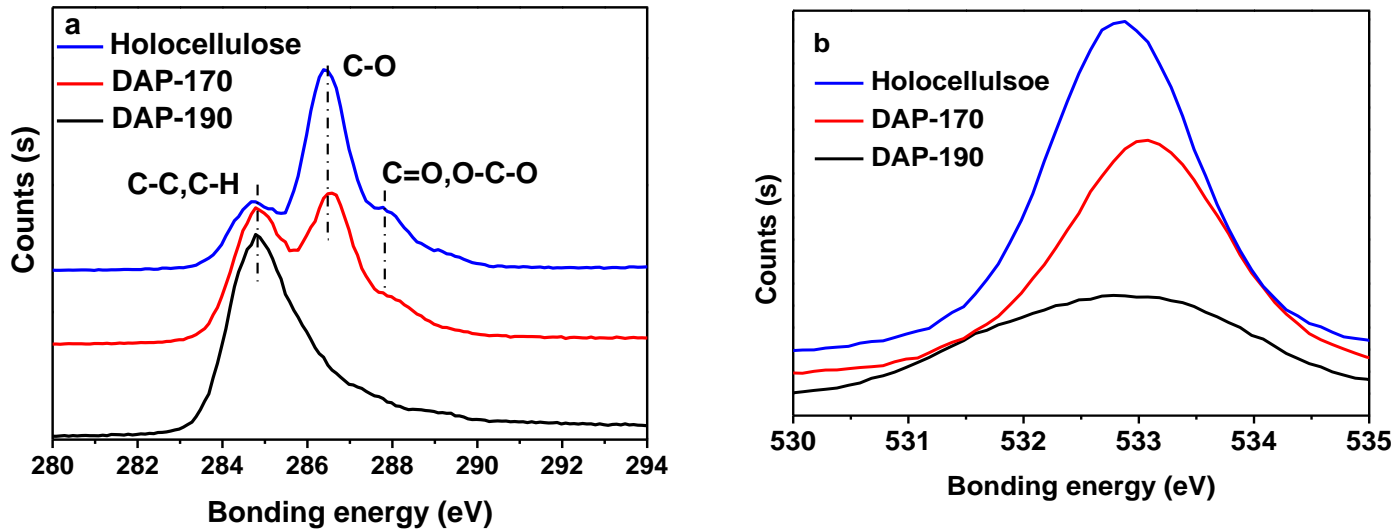

Fig. 2. XPS spectra of holocellulose and residues obtained from DAPs at 170 and $190{ }^{\circ} \mathrm{C}$

\section{Accessibilities and Hydrophobicities}

With regard to the digestibility of the lignocellulose, cellulose accessibility is a more important factor than the chemical composition, delignification, and cellulose crystallinity (Karimi and Taherzadeh 2016). Thus, increasing the accessibility for enzymes is one of the main objectives of pretreatment. Simons' staining method is used to estimate the accessibility of lignocellulose. In this method, DO molecules have a similar diameter as a typical enzyme and can be used to estimate the accessibility of substrate for cellulase. The ratio of DO and DB indicates the relative amount of large pores to small pores.

Figure 3 shows that LHW pretreatments and DAPs increased accessibility of holocellulose. After pretreatments, the absorbed DO and total dyes on samples increased from 15.1 to $74.6 \mathrm{mg} / \mathrm{g}$ (LHW-150) and from 73.7 to $192.6 \mathrm{mg} / \mathrm{g}$ (LHW-150), respectively. Residue from DAP at $130{ }^{\circ} \mathrm{C}$ adsorbed a similar level of total dyes as the LHW-150 but had a larger $\mathrm{O} / \mathrm{B}$ ratio (0.784). This result might be due to the fact that acidic conditions cause degradation of a larger amount of xylans than the LHW pretreatments, releasing larger pores. This phenomenon was consistent with the composition analysis; the content of xylans in DAP-130 (7.0\%) was less than that in LHW-150 (17.1\%). However, further degradation of xylans caused the collapse of pores, decreasing cellulose accessibility to $160.0 \mathrm{mg} / \mathrm{g}$ (DAP-150 with 5.1\% xylans).

In samples DAP-170 and DAP-190, the contents of xylans were reduced to undetectable and caused a decrease of substrate accessibilities to 131.3 and $96.4 \mathrm{mg} / \mathrm{g}$, respectively. These results might be ascribed to the deposition of pseudo-lignin during its condensation onto the surface of materials, thus hindering the diffusion of the dye molecules into the substrates (Sannigrahi et al. 2011; Xiao et al. 2011). Compared with other studies, the accessibilities of the substrates from LHW pretreatments and DAPs of sugarcane bagasse holocellulose was much higher than that of DAPs of Populus for 0 to 60 min (Meng et al. 2013; 2015). The higher accessibility of untreated holocellulose was mainly due to the looser cell wall structure of sugarcane bagasse. The effect of delignification on cellulose accessibility is limited (Kumar and Wyman 2009; Meng and Raguakas 2014). Long pretreatment times increased the accessibility slightly above that from DAP of Populus at $160{ }^{\circ} \mathrm{C}$ for $1 \mathrm{~h}$ (Meng et al. 2015). 


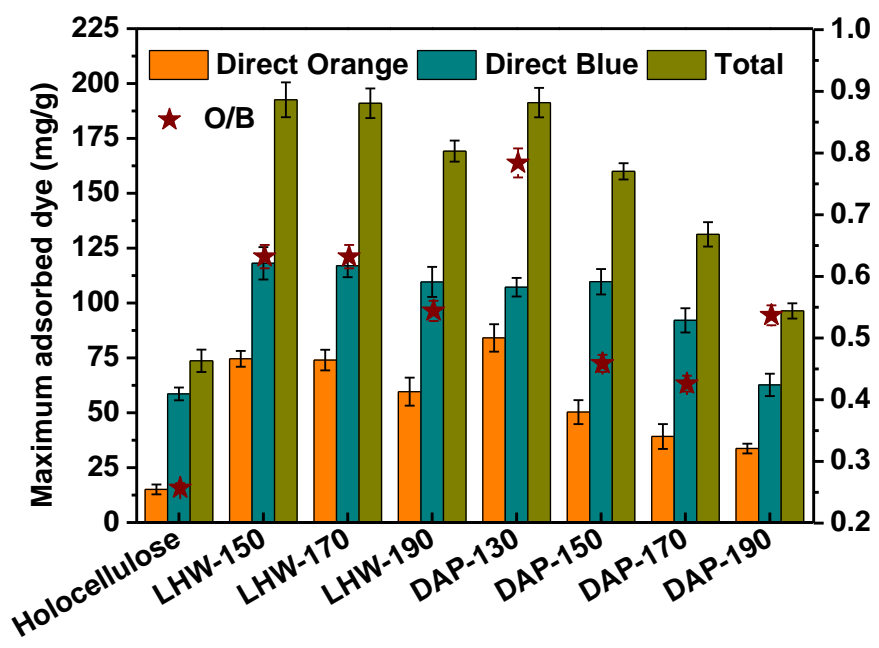

Fig. 3. Accessibilities of holocellulose and residues obtained from pretreatments

The removal of xylans increases cellulose accessibility and changes hydrophobicities of substrates (Kumar and Wyman 2009). The effects of LHW pretreatments and DAPs on hydrophobicities of samples are shown in Table 2. After LHW pretreatments and DAPs at 130 and $150{ }^{\circ} \mathrm{C}$, the hydrophobicities of samples ranged between 18.7 and $32.3 \mathrm{~L} / \mathrm{g}$. The slight increase of hydrophobicities of substrates after pretreatments was attributed to the fact that ordered cellulose is more hydrophobic than amorphous xylans. The results from XRD indicated that pretreatment degraded amorphous xylans and cellulose, increasing the CrI of samples from 39.1 to 57.8. However, the residue after LHW pretreatment at $150{ }^{\circ} \mathrm{C}$ had lower hydrophobicity as than holocellulose. Thus, under this condition LHW pretreatment removed acetyl groups rather than the xylans. Kumar and Wyman (2009) suggested that acetyl groups may restrict cellulose accessibility by changing its hydrophobicity. The hydrophobicities of substrates DAP-170 and DAP190 increased to 65.5 and $113.4 \mathrm{~L} / \mathrm{g}$ as the pseudo-lignin contents increased to $34.4 \%$ and 93.6\%, respectively. These results were ascribed to the fact that pseudo-lignin had more hydrophobic function groups than carbohydrates, which was consistent with the decreased $\mathrm{O}$ contents and increased intensity of signal for C-C bonds in XPS spectra.

Table 2. Crystalline Indexes (Crl) and Surface Hydrophobicities of Holocellulose and Residues from Pretreatments

\begin{tabular}{|c|c|c|c|c|c|c|c|c|}
\hline & Holocellulose & LHW-150 & LHW-170 & LHW-190 & Acid-130 & Acid-150 & Acid-170 & Acid-190 \\
\hline Crl & 39.1 & 46.0 & 47.4 & 51.6 & 48.6 & 53.2 & 57.8 & 23.4 \\
\hline $\begin{array}{c}\text { Hydrophobicity } \\
\text { (L/g) }\end{array}$ & 26.5 & 18.7 & 27.1 & 30.1 & 28.6 & 32.3 & 65.5 & 113.4 \\
\hline
\end{tabular}

\section{Enzymatic Hydrolysis and Fermentation}

LHW pretreatments and DAPs introduced pseudo-lignin condensation, and changes of accessibility and hydrophobicity, which affected the combination between cellulase and substrate. Enzymatic hydrolysis conversions of samples after pretreatments are shown in Fig. 4a. The initial and final enzymatic conversion of holocellulose were observed as $10.4 \%$ and $53.2 \%$, respectively. LHW pretreatments achieved an enhancement of cellulose conversion, increasing initial and final conversions to $13.9 \%$ and $82.4 \%$ (LHW-170), respectively. As pretreatment temperature increased to $190{ }^{\circ} \mathrm{C}$, initial and 
final glucan conversion decreased to $9.9 \%$ and $70.4 \%$, respectively. The decrease might be ascribed the higher CrI of samples LHW-190 than other residues from LHW pretreatments (Table 2). DAP at $130{ }^{\circ} \mathrm{C}$ further improved final glucan conversion to $85.3 \%$ with initial conversion of $12.8 \%$. However, further increases in temperature of DAPs to 150 to $190{ }^{\circ} \mathrm{C}$ caused an increase of $\mathrm{CrI}$ and decreases in both initial and final glucan conversions of residues. After pretreatments, the enhancement of initial glucan conversion was due to the degradation of xylans. Xylans can act as a barrier to enzymatic hydrolysis (Wiman et al. 2012). Removal of physical barriers enhances the availability of substrates and improves initial carbohydrate conversion (Pihlajaniemi et al. 2016).

The final glucan conversion was negatively correlated with contents of pseudolignin in the residues. DAPs generated a larger amount of pseudo-lignin than LHW pretreatments at the same temperature. In this study, DAPs at 150,170 , and $190{ }^{\circ} \mathrm{C}$ formed $5.4 \%, 34.3 \%$, and $93.6 \%$, respectively, resulting in declines of glucose yields via enzymatic hydrolysis to $63.0 \%, 45.6 \%$, and $39.9 \%$, respectively. The initial glucose conversion of these samples also decreased to $9.9 \%, 6.4 \%$, and $6.0 \%$, respectively. These decreases reflect that pseudo-lignin forms physical barriers to prevent enzyme access to substrates, which decreases glucose yields. In addition, the pseudo-lignin contains hydrophobic groups that irreversibly bind to enzymes through hydrophobic interaction and inhibit enzyme activity ( $\mathrm{Hu}$ et al. 2012).

The negative effect of pseudo-lignin on initial and final glucose conversion has also been confirmed by previous studies (Hu et al. 2012, 2013; Kumar et al. 2013; He et al. 2018). Xylans derived pseudo-lignin significantly retards cellulose hydrolysis, resulting in a $25 \%$ drop in cellulose conversion even with a negligible amount of pseudo-lignin after dilute acid pretreatment of xylan-Avicel mixture. The pseudo-lignin in the mixture also decreases the initial and final glucose conversion (Kumar et al. 2013). Pseudo-lignin from acid pretreatment of poplar holocellulose also inhibits the enzymatic hydrolysis of poplar holocellulose. When the pseudo-lignin increases from $10 \%$ to $40 \%$, cellulose conversion decreases from $74 \%$ to $46 \%$ (Hu et al. 2012).

Holocellulosic residues with different amounts of pseudo-lignin were also submitted to SSF to production bioethanol; the yields of bioethanol are shown in Fig. 4b. LHW pretreatments and low temperature DAPs enhanced bioethanol production. The bioethanol yields were consistent with glucose conversion of enzymatic hydrolysis. After LHW pretreatments and DAPs, residues (LHW-170 and DAP-130) had higher ethanol yield as compared to other residues $(12.8 \mathrm{~g} / \mathrm{L}$ and $13.1 \mathrm{~g} / \mathrm{L}$, respectively), which was consistent with the results of enzymatic hydrolysis. However, samples LHW-150, LHW190, and DAP-150 had different enzymatic conversions, but a similar bioethanol production, as these residues contained similar amounts of cellulose. The bioethanol yields decreased to 6.3 and $0.5 \mathrm{~g} / \mathrm{L}$ via fermentation of DAP-170 and DAP-190, respectively. The drop of bioethanol yield was because DAPs at 170 and $190{ }^{\circ} \mathrm{C}$ decreased the residual cellulose contents in substrates. In addition, large amounts of pseudo-lignin in these samples retarded bioethanol production.

Pseudo-lignin negatively affects the growth and metabolism of yeast. The number of yeast cells in the fermentation broth were counted. After fermentation for $24 \mathrm{~h}$, there were $9.5 \times 10^{5}$ yeast cells in the holocellulose fermentation broth. The fermentation broths of residues obtained from LHW pretreatments DAP-130 and DAP-150 contained a similar number of yeast cells $\left(4.0 \times 10^{5}\right)$. However, as the pseudo-lignin contents increased in substrates, the number of yeast cells decreased to $1.5 \times 10^{5}$ and $1.3 \times 10^{5}$ in the fermentation broths of DAP-170 and DAP-190, respectively. The inhibition mechanism of pseudo-lignin on yeast growth and metabolism will be considered in a future study. 

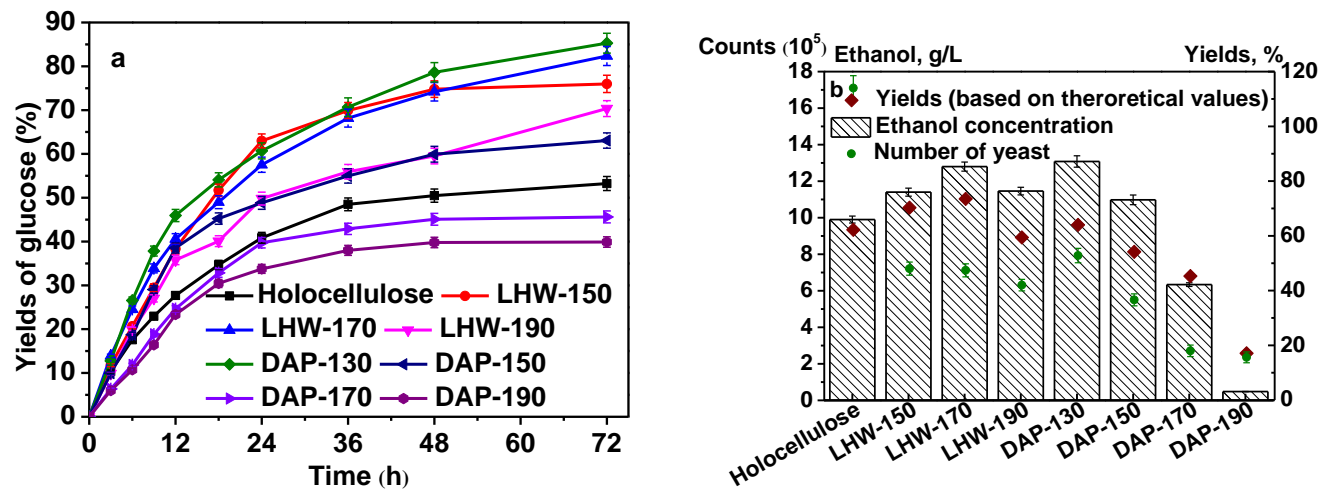

Fig. 4. Enzymatic hydrolysis (a) and SSF (b) of holocellulose and residues obtained from pretreatments.

\section{CONCLUSIONS}

1. Liquid hot water (LHW) pretreatments and dilute acid pretreatments (DAPs) degraded holocellulose and generated pseudo-lignin, accounting $2.1 \%$ to $93.6 \%$ of the residues.

2. Increasing pretreatment temperature caused degradation of a large amount of xylans and certain amount of cellulose, increasing accessibilities of residues.

3. Dilute acid pretreatment at $130{ }^{\circ} \mathrm{C}$ introduced the maximum glucose and bioethanol yields of substrate via enzymatic hydrolysis and SSF as $85.3 \%$ and $13.1 \mathrm{~g} / \mathrm{L}$, respectively.

4. Accumulation of pseudo-lignin after pretreatment with dilute acid at $170{ }^{\circ} \mathrm{C}$ led to an increase of hydrophobicities of residues, impeding bioconversion of residue and reducing glucose and ethanol yields to $45.6 \%$ and $6.3 \mathrm{~g} / \mathrm{L}$, respectively.

\section{ACKNOWLEDGMENTS}

The authors are grateful to the funding support from the Key Laboratory of State Forestry and Grassland Administration on Highly-Efficient Utilization of Forestry Biomass Resources in Southwest China (2020-KF05), Key Laboratory for Forest Resources Conservation and Utilisation in the Southwest Mountains of China, Ministry of Education, Southwest Forestry University (KLESWFU-201807), Yunnan Provincial Department of Education (2020J0398), and the Open Fund of Guangxi Key laboratory of Chemistry and Engineering of Forest Products (GXFC-08).

\section{REFERENCES CITED}

Chandra, R., Ewanick, S., Hsieh, C., and Saddler, J. N. (2008). "The characterization of pretreated lignocellulosic substrates prior to enzymatic hydrolysis, Part 1: A modified Simons' staining technique," Biotechnol. Prog. 24(5), 1178-1185. DOI: 10.1002/btpr.33

Chuntanapum, A., and Matsumura, Y. (2009). "Formation of tarry material from 5-HMF 
in subcritical and supercritical water," Ind. Eng. Chem. Res. 48, 9837-9846. DOI: 10.1021/ie900423g

Desouky, S. E.-S., El-Gamal, S., Ragab, T. I. M., Bayoumy, S., and Khattab, A.-R. M. (2014). "Established an effective multi-function system for sugarcane bagasse biodegradation," Int. J. Sci. Eng. Res. 5, 1-8.

Gessner, A., Waicz, R. A., Lieske, A., Paulke, B.-R., Mäder, K., and Müller, R. H. (2000). "Nanoparticles with decreasing surface hydrophobicities: Influence on plasma protein adsorption," Int. J. Pharm. 196, 245-249. DOI: 10.1016/S03785173(99)00432-9

He, J., Huang, C. X., Lai, C. H., Huang, C, Li, X., and Yong, Q. (2018). "Elucidation of structure-inhibition relationship of monosaccharides derived pseudo-lignin in enzymatic hydrolysis," Ind. Crop. Prod. 113, 368-375. DOI:

10.1016/j.indcrop.2018.01.046

He, Y., Pang, Y., Liu, Y., Li, X., and Wang, K. (2008). "Physicochemical characterization of rice straw pretreated with sodium hydroxide in the solid state for enhancing biogas production," Energy Fuels 22, 2775-2781. DOI: 10.1021/ef8000967

Himmel, M. E., Ding, S. Y., Johnson, D. K., Adney, W. S., Nimlos, M. R., Brady, J. W., and Foust, T. D. (2007). "Biomass recalcitrance: Engineering plants and enzymes for biofuels production," Science 315, 804-807. DOI: 10.1126/science.1137016

Hu, F., Jung, S., and Ragauskas, A. J. (2012). "Pseudo-lignin formation and its impact on enzymatic hydrolysis," Bioresource Technol. 117, 7-12. DOI:

10.1016/j.biortech.2012.04.037

Hu, F., Jung, S., and Ragauskas, A. J. (2013). "Impact of pseudolignin versus dilute acidpretreated lignin on enzymatic hydrolysis of cellulose," ACS Sustainable Chem. Eng. 1, 62-65. DOI: 10.1021/sc300032j

Hu, F., Ragauskas, A.J., (2014). "Suppression of pseudo-lignin formation under dilute acid pretreatment conditions," $R S C A d v$. 4, 4317-4323. DOI: 10.1039/c3ra42841a

Jung, S., Foston, M., Sullards, M., and Ragauskas, A. J. (2010). "Surface characterization of dilute acid pretreated Populus deltoides by ToF-SIMS," Energy Fuels 24, 1347 1357. DOI: $10.1021 /$ ef901062p

Karimi, K., and Taherzadeh, M. J. (2016). "A critical review on analysis in pretreatment of lignocelluloses: Degree of polymerization, adsorption/desorption, and accessibility," Bioresource Technol. 203, 348-356. DOI:

10.1016/j.biortech.2015.12.035

Kocaefe, D., Huang, X., Kocaefe, Y., and Boluk, Y. (2013). “Quantitative characterization of chemical degradation of heat-treated wood surface during artificial weathering using XPS," Surf. Interace Anal. 45, 639-649. DOI: 10.1002/sia.5104

Kumar, R., Hu, F., Sannigrahi, P., Jung, S., Ragauskas, A. J., and Wyman, C. E. (2013). "Carbohydrate derived-pseudo-lignin can retard cellulose biological conversion," Biotechnol. Bioeng. 110, 737-753. DOI: 10.1002/bit.24744

Kumar, R., and Wyman, C. E. (2009). "Cellulase adsorption and relationship to features of corn stover solids produced by leading pretreatments," Biotechnol. Bioeng. 103, 252-267. DOI: 10.1002/bit.22258

Leschinsky, M., Webber, H. K., Patt, R., and Sixta, H. (2009). "Formation of insoluble components during autohydrolysis of Eucalyptus globulus," Lenzinger Berichte 87, 16-25. DOI: 242458866

Li, J., Henriksson, G., and Gellerstedet, G. (2005). "Carbohydrate reactions during hightemperature steam treatment of aspen wood," Appl. Biochem. Biotechnol. 175, 175187. DOI: 10.1385/abab:125:3:175 
Luijkx, G. C. A., Vanrantwijk, F., and Vanbekkum, H. (1993). "Hydrothermal formation of 1,2,4-benzenetriol from 5-hydroxymethyl-2-furaldehyde and D-fructose," Carbohyd. Res. 242, 131-139. DOI: 10.1016/0008-6215(93)80027-c

Ma, X. J., Yang, X. F., Zheng, X., Chen, L. H., Huang, L. L., Cao, S. L., and Akinosho, H. (2015). "Toward a further understanding of hydrothermally pretreated holocellulose and isolated pseudo lignin," Cellulose 22, 1687-1696. DOI: 10.1007/s10570-015-0607-1

Maurya, D. P., Singla, A., and Negi, S. (2015). "An overview of key pretreatment processes for biological conversion of lignocellulosic biomass to bioethanol," 3 Biotech. 5, 597-609. DOI: 10.1007/s13205-015-0279-4

Meng, X., Foston, M., Leisen, J., DeMartini, J., Wyman, C. E., and Ragauskas, A. J. (2013). "Determination of porosity of lignocellulosic biomass before and after pretreatment by using Simons' stain and NMR techniques," Bioresource Technol. 144, 467-476. DOI: 10.1016/j.biortech.2013.06.091

Meng, X. Z., and Ragauskas, A. J. (2014). "Recent advances in understanding the role of cellulose accessibility in enzymatic hydrolysis of lignocellulosic substrates," Curr. Opin. Biotech. 27, 150-158. DOI: 10.1016/j.copbio.2014.01.014

Meng, X. Z., Wells Jr., T., Sun, Q. N., Huang, F., and Ragauskas, A. J. (2015). "Insights into the effect of dilute acid, hot water or alkaline pretreatment on the cellulose accessible surface area and the overall porosity of Populus," Green Chem. 17, 42394246. DOI: $10.1039 / \mathrm{c5gc00689a}$

Pihlajaniemi, V., Sipponen, M. H., Liimatainen, H., Sirviö, J. A., Nyyssölä, A., and Laakso, S. (2016). "Weighing the factors behind enzymatic hydrolyzability of pretreatment lignocellulose," Green Chem. 18, 1295-1305. DOI: 10.1039/c5gc01861g

Popoff, T., and Theandee, O. (1972). "Formation of aromatic compounds from carbohydrates. Part 1. Reaction of D-glucuronic acid, D-galacturonic acid, D-xylose, and Larabinose in slightly acidic, aqueous solution," Carbohyd. Res. 22, 135-149. DOI: 10.1016/S0008-6215(00)85733-X

Sannigrahi, P., Kim, D. H., Jung, S., and Ragauskas, A. J. (2011). "Pseudo-lignin and pretreatment chemistry," Energ. Enviro. Sci. 4, 1306-1310. DOI:

10.1039/C0EE00378F

Shinde, S. D., Meng, X. Z., Kumar, R., and Ragauskas, A. J. (2018). "Recent advances in understanding the pseudo-lignin formation in a lignocellulosic biorefinery," Green Chem. 10, 2192-2205. DOI: 10.1039/c8gc00353j

Sluiter, A., Hames, B., Ruiz, R., Scarlata, C., Sluiter, J., Templeton, D., and Crocker, D. (2012). Determination of Structural Carbohydrates and Lignin in Biomass (NREL/TP-510-42618), National Renewable Energy Laboratory, Golden, CO, USA.

Wiman, M., Dienes, D., Hansen, M. A. T., van der Meulen, T., Zacchi, G., and Lidén, G. (2012). "Cellulose accessibility determines the rate of enzymatic hydrolysis of steampretreated spruce," Bioresource Technol. 126, 208-215. DOI:

10.1016/j.biortech.2012.08.082

Xiao, L. P., Sun, Z. J., Shi, Z. J., Xu, F., and Sun, R. C. (2011). "Impact of hot compressed water pretreatment on the structural changes of woody biomass for bioethanol production," BioResources 6(2), 1576-1598. DOI: 10.15376/biores.6.2. 1576-1598

Yang, H. Y., Wang, K., Xu, F., Sun, R. C., and Liu, Y. B. (2012). "H2SO4-Catalyzed hydrothermal pretreatment of triploid poplar to enhance enzymatic hydrolysis," Ind. Eng. Chem. Res. 51, 11598-11604. DOI: 10.1021/ie300895y

Yang, H. Y., Chen, J. H., Chen, Q., Wang, K., and Sun, R. C. (2015). “The synergic 
relationship between xylan removal and enhanced cellulose digestibility for bioethanol production: Reactive area, crystallinity, and inhibition," BioEnerg. Res. 8, 1847-1855. DOI: $10.1007 / \mathrm{s} 12155-015-9642-\mathrm{x}$

Zhuang, J. S., Wang, X. J., Xu, J. Y., Wang, Z. J., and Qin, M. H. (2017). "Formation and deposition of pseudo-lignin on liquid-hot-water-treated wood during cooling process," Wood Sci. Technol. 51, 165-174. DOI: 10.1007/s00226-016-0872-7

Article submitted: February 19, 2021; Peer review completed: March 28, 2021; Revised version received and accepted: April 16, 2021; Published: April 22, 2021.

DOI: $10.15376 /$ biores.16.2.4052-4063 